This item was submitted to Loughborough's Research Repository by the author.

Items in Figshare are protected by copyright, with all rights reserved, unless otherwise indicated.

\title{
Exploring metastable defect behavior in solution-processed antimony doped CIGS thin film solar cells
}

PLEASE CITE THE PUBLISHED VERSION

https://doi.org/10.1109/PVSC.2018.8547492

PUBLISHER

(C) IEEE

VERSION

AM (Accepted Manuscript)

LICENCE

CC BY-NC-ND 4.0

\section{REPOSITORY RECORD}

Togay, Mustafa, Sona Ulicna, Syeda Bukhari, Fabiana Lisco, Martin Bliss, Alexander Eeles, Michael Walls, and Jake W. Bowers. 2019. "Exploring Metastable Defect Behavior in Solution-processed Antimony Doped CIGS Thin Film Solar Cells". figshare. https://hdl.handle.net/2134/36416. 


\title{
Exploring metastable defect behavior in solution-processed antimony doped CIGS thin film solar cells
}

\author{
Mustafa Togay, Soňa Uličná, Syeda Bukhari, Fabiana Lisco, Martin Bliss, Alex Eeles, John M. Walls and \\ Jake W. Bowers
CREST, Wolfson School of Mechanical, Electrical and Manufacturing Engineering, Loughborough University, Loughborough, Leicestershire, LE11 3TU, UK

\begin{abstract}
This study investigates the metastable defect behavior from temperature dependent current density-voltage (JVT) and capacitance spectroscopy measurements in solutionprocessed antimony (Sb) doped CIGS thin film solar cells. From the $V_{o c}(T)$ analysis, the main recombination mechanism is found to be Schottky-Read-Hall recombination in the bulk. A detailed study of the carrier concentration, defect density and energy level defects was performed using capacitance spectroscopy. Admittance spectroscopy measurements revealed an admittance step at low temperatures with an activation energy of $\mathbf{4 2} \mathbf{m e V}$.

Index Terms - antimony, solution-processed, CIGS, carrier concentration, defect levels.
\end{abstract}

\section{INTRODUCTION}

Thin film solar cells based on polycrystalline $\mathrm{Cu}(\mathrm{In}, \mathrm{Ga}) \mathrm{Se}_{2}$ (CIGS) absorbers are one of the most promising candidates for low-cost and efficient large-scale solar energy conversion devices. Power conversion efficiencies of CIGS thin film solar cells exceed $\sim 22 \%$ in laboratory-scale devices [1]. To reduce fabrication costs, solution-processing of CIGS absorbers is an attractive prospect. So far, the best performing solutionprocessed CIGS solar cell with a power conversion efficiency (PCE) of $15.2 \%$ was developed using hydrazine as a solvent [2]. Nonetheless, using hydrazine raises safety concerns as it is highly toxic and explosive. As a safer alternative, a solvent combination based on an amine-thiol can be used to dissolve metal chalcogenides effectively for use in solution processed thin film solar cells and is presented here [3].

Despite improvements in solution-processed CIGS solar cells and significant progress in understanding of their electrical properties, the limiting factors of device performance have not yet been explained satisfactorily [4]. Capacitance spectroscopy can be used as a tool to identify the discrete traps in thin film solar cells [5]. It covers a range of measurement methods including drive-level capacitance profiling (DLCP), admittance spectroscopy (AS) and capacitance-voltage (C-V) profiling techniques. Each technique provides useful information about carrier concentration, density of states, defect concentration and the activation energy of defect levels. Efficiencies of CIGS solar cells are affected by these properties, especially in solution processed devices, and their determination is important for understanding limiting factors of the device performance.
The purpose of this work is to investigate the metastable behavior of antimony doped solution-processed CIGS solar cells using electrical and optical measurements. CIGS absorbers were fabricated using metal chalcogenides dissolved in an amine-thiol solvent mixture and combined with antimony ( $\mathrm{Sb}$ ) as a dopant, in an effort to enhance the grain growth of CIGS, and improve the electronic properties of the device[6]. However, excessive doping can cause reduced grain growth, if not carefully controlled. Devices have been characterized by current density-voltage (J-V), capacitance spectroscopy, external quantum efficiency (EQE), scanning electron microscopy (SEM) and electroluminescence (EL) imaging.

\section{EXPERIMENTAL}

\section{A. Instrumentation}

The temperature dependent electrical measurements were carried out in an evacuated closed-cycle helium cryostat with a measurement range of 105 to $315 \mathrm{~K}$ (Fig. 1). The device temperature was adjusted using a LakeShore 335 temperature controller with the temperature measured by a $\mathrm{Si}$ diode attached to the bottom of the sample stage and a thermocouple. Prior to cooling, the samples were kept in the dark for one hour to ensure a relaxed state.

The J-V characteristics were measured using an ABET solar simulator under $1000 \mathrm{~W} / \mathrm{m}^{2}$ illumination, calibrated using a reference Si photodiode.

Admittance spectroscopy was performed with a Keysight E4990 impedance analyzer. Drive level capacitance profiling (DLCP) and capacitance-voltage profiles were obtained using the same setup at a frequency of $100 \mathrm{kHz}$, with bias sweep from $-1 \mathrm{~V}$ to $1 \mathrm{~V}$ at room temperature. JVT curves were acquired using a Keysight B2902A source-measurement unit using the same cryostat and the same electrical contacts utilized for the capacitance measurements. The samples were illuminated under $500 \mathrm{~W} / \mathrm{m}^{2}$ with a halogen light source.

The external quantum efficiency (EQE) spectra were acquired with chopped light using a Bentham PVE300 system. The measurements were performed at $0 \mathrm{~V}$ bias with a spectral resolution of $5 \mathrm{~nm}$. 
The film morphology was investigated using a Carl Zeiss 1530 VP field emission gun scanning electron microscope (FEGSEM) with $30 \mu \mathrm{m}$ aperture size and $5 \mathrm{kV}$ operation voltage.

The Electroluminescence (EL) images were obtained using an Apogee Alta F800 camera, with a Qioptiq Inspec X IR lens and an aperture f-stop of 2.8. Forward bias was applied to each cell with a current injection $\sim J_{s c}$ and images were collected with a 10 minute acquisition time.



Fig. 1. Schematic of experimental setup for electrical measurements.

\section{B. Device preparation and fabrication}

The CIGS devices were fabricated using a molecular solution approach currently being developed at CREST [7]. This approach involves the spray deposition of metal sulphide solutions, based on a dithiol-diamine solvent combination. The preparation starts with the deposition of a $\sim 30 \mathrm{~nm}$ thick $\mathrm{MoN}_{\mathrm{x}}$ layer onto a $600 \mathrm{~nm}$ thick Mo coated soda-lime glass (SLG) substrate by DC magnetron sputtering. This layer acts as a diffusion barrier against selenium (Se). Then a $\sim 50 \mathrm{~nm}$ thick Mo layer was deposited on top of the $\mathrm{MoN}_{\mathrm{x}}$ layer. $\mathrm{Cu}(\mathrm{In}, \mathrm{Ga}) \mathrm{Se}_{2}$ solutions were prepared using $\mathrm{Cu}_{2} \mathrm{~S}, \mathrm{In}_{2} \mathrm{~S}_{3}$ and elemental $\mathrm{Ga}$ with $\mathrm{Se}$ precursors dissolved in 1,2ethanedithiol/1,2-ethylenediamine $(1 / 10 \mathrm{v} / \mathrm{v})$ solvent mixture. $2 \mathrm{~mol} \%$ of $\mathrm{Sb}$ acetate was added to the precursor solution. The final solution was then deposited by hand-spraying onto the Mo coated substrates with aimed composition of $\mathrm{Cu}_{0.9} \mathrm{In}_{0.7} \mathrm{Ga}_{0.3} \mathrm{Se}_{2}$ and thickness of approximately $2 \mu \mathrm{m}$. The as-deposited films were then selenized in a graphite box, inside a tube furnace for 90 minutes at $540^{\circ} \mathrm{C}$. A buffer layer of $\mathrm{CdS}(\sim 50 \mathrm{~nm})$ was then deposited by chemical bath deposition (CBD) followed by window i- $\mathrm{ZnO}$ and $\mathrm{Al}: \mathrm{ZnO}$ layers both deposited using RF sputtering ( 50nm and 500 $\mathrm{nm}$, respectively). Finally, $500 \mathrm{~nm}$ thick front contact silver grids were deposited by thermal evaporation. The details of the solution preparation and techniques used in the fabrication of CIGS devices are provided in our previous work [3].

\section{RESULTS}

\section{A. Admittance Spectroscopy}

The admittance measurement under equilibrium conditions ( $0 \mathrm{~V}$ bias) for the $\mathrm{Sb}$ doped device shows an admittance step at low temperatures (between $265 \mathrm{~K}$ and $105 \mathrm{~K}$ ) and high frequencies (Fig. 2). This admittance step is often discussed in the literature as the N1 response, commonly associated with spatially discrete distribution of donor-like defects at the surface of the absorber layer. It has typical activation energies, $E_{A}$, between $40 \mathrm{meV}$ and $160 \mathrm{meV}$ [8]. $E_{A}$ can be obtained from the slope of the Arrhenius plot of the inflection points determined from the maxima of the conductance spectra (Fig. 3 ) and is estimated to be $42 \mathrm{meV}$ which can correspond to the N1 defect.

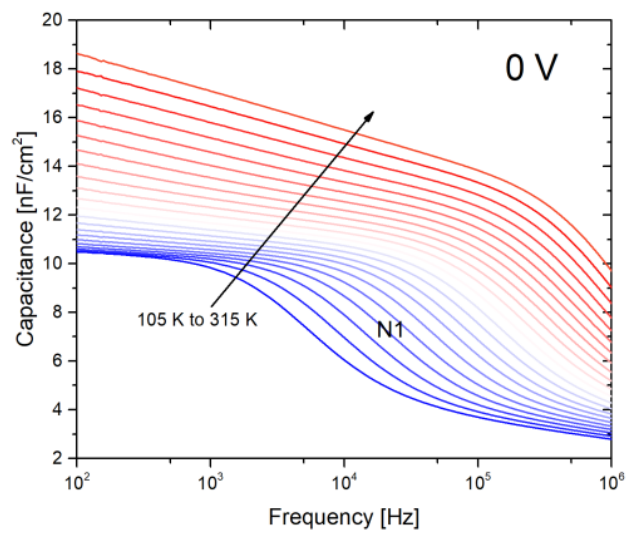

Fig. 2. Admittance spectra in the dark at $0 \mathrm{~V}$ between 105 and 315 $\mathrm{K}$. An admittance step is visible between $265 \mathrm{~K}$ and $105 \mathrm{~K}$ which is marked as "N1".

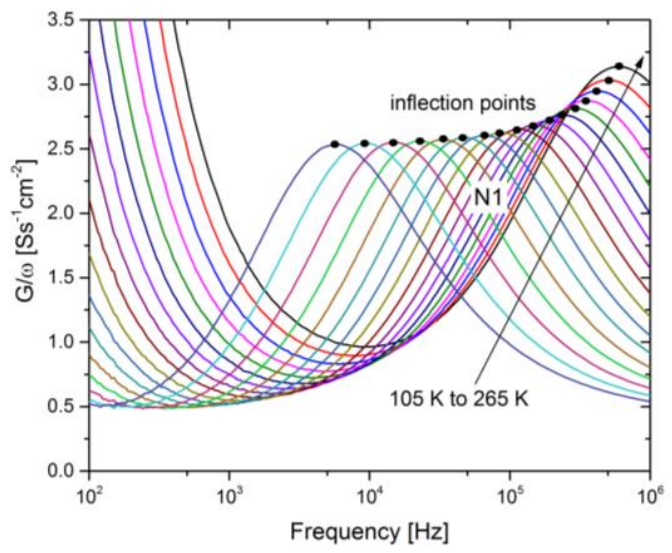

Fig. 3. Conductance spectra between 105 and $265 \mathrm{~K}$ for the N1 step, $\omega$ being the angular emission frequency of the inflection points. Inflection points are marked in black at the maxima of each curve. 


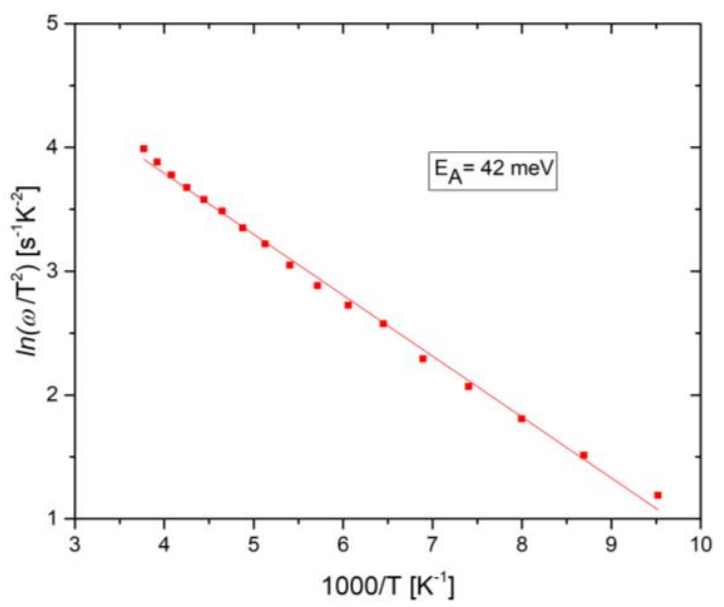

Fig. 4. (a) Arrhenius plot of the inflection points derived from conductance spectra in Fig. 3.

\section{B. Capacitance-Voltage Analysis}

Capacitance profiles were measured by means of the DLCP and $\mathrm{C}-\mathrm{V}$ profiling techniques, shown in Fig. 5. Both methods showed typical U-shaped depth profiles commonly reported in literature [9], with the DLCP measurement featuring an improved signal-to-noise ratio. The use of DLCP gives a more accurate determination of carrier concentration. Likewise, $\mathrm{C}-\mathrm{V}$ profiling can lead to incorrect determination due to the presence of deep defects or interface defects.

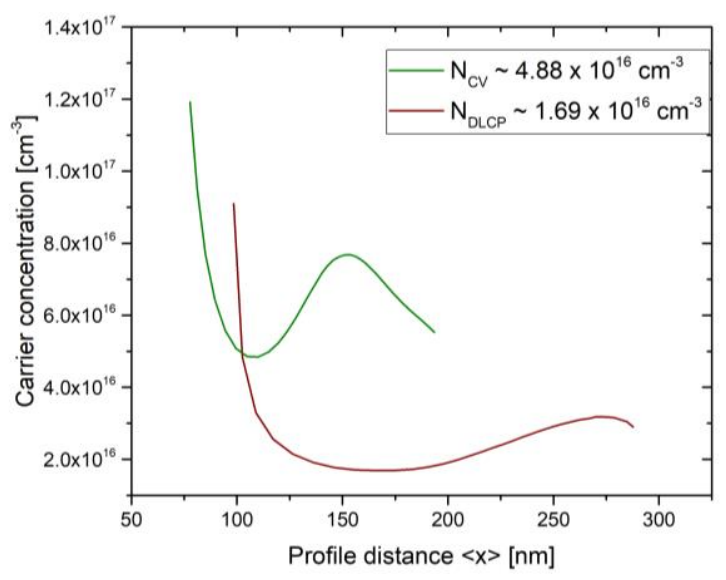

Fig. 5. Comparisons between DLCP and C-V depth profiles of the best cell, at room temperature. Carrier concentration values are extracted from the lowest point of the curves.

DLCP measures the change in junction capacitance with a varying peak to peak oscillating voltage (drive level). It allows an estimation of the defect concentration from both shallow and deep defects [10]. Assuming a small enough drive level amplitude $(\delta V)$, the capacitance can be estimated as $C \approx C_{0}+$ $C_{1}(\delta V)$ where $C_{0}$ can be denoted as the capacitance in the limit of zero drive level and $C_{1}$ as the first order correction to the junction capacitance for finite drive level [11]. These two parameters can be used to determine the bulk defect concentration $\left(N_{D L C P}\right)$, including both the carrier concentration and the deep level defect states that can respond at the signal frequency. Defining the area of the cell $\mathrm{A}, \mathrm{q}$ as the charge of an electron and $\varepsilon$ as the dielectric constant of the material, then

$$
N_{D L C P}=-\frac{C_{0}^{3}}{2 q \varepsilon A^{2} C_{1}}
$$

In both cases, the depth profiles have an unusual shape, with a tail off towards the back contact. Typically, solution grown CIGS films form a bilayer structure of a large-grain top layer which covers a fine-grain bottom layer. We suggest this causes the tail off as the depletion width crosses the interface between the two layers during the voltage sweep. A difference in the carrier concentration of roughly $3.19 \times 10^{16} \mathrm{~cm}^{-3}$ was observed from the different techniques. As the $\mathrm{C}-\mathrm{V}$ profiles are affected by interface states, DLCP profiles were used to estimate the carrier concentration for this study. The best cell showed a carrier concentration of $1.69 \times 10^{16} \mathrm{~cm}^{-3}$.

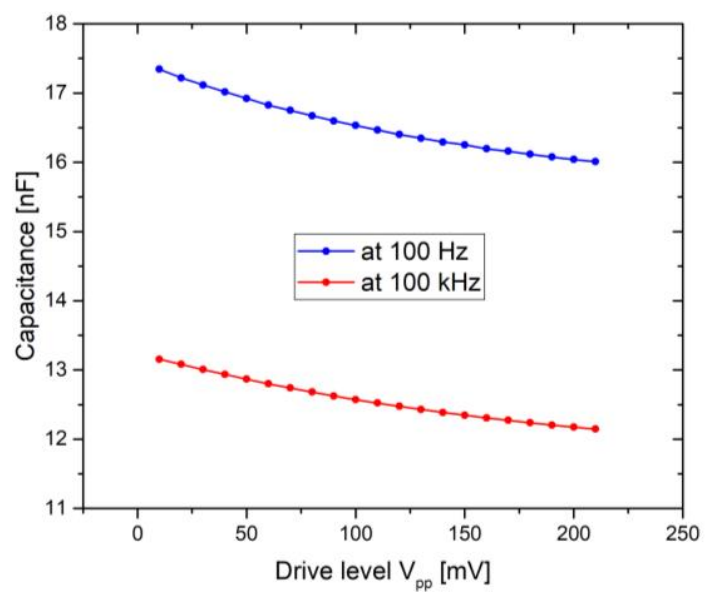

Fig. 6. Capacitance versus drive level (peak-to-peak voltage) measured at $100 \mathrm{~Hz}$ and $100 \mathrm{kHz}$ to extract $C_{0}$ and $C_{l}$ values to estimate the carrier concentration and defect density in Fig. 7.

The defect density was measured by DLCP at zero bias and room temperature. Capacitance data were recorded at 21 drive levels spaced by intervals of $10 \mathrm{mV}$ over a range of $10 \mathrm{mV}$ to $210 \mathrm{mV}$, where these values represent the amplitude of the oscillating voltage (drive level). At each drive level, measurements were recorded at 77 frequencies on a log scale. The measurement range should extend to the highest frequency possible, as only shallow defects respond at these frequencies. However, if the frequency is too high, measurements are affected by series resistance of the probes. For this reason, the measurements were limited from $100 \mathrm{~Hz}$ to $100 \mathrm{kHz}$. At $100 \mathrm{~Hz}$ and $100 \mathrm{kHz}$, the capacitance was plotted versus the oscillating voltage (Fig. 6) in order to extract the values of $C_{0}$ and $C_{l}$. The defect density at $100 \mathrm{kHz}$ was interpreted as the carrier concentration of $1.69 \times 10^{16} \mathrm{~cm}^{-3}$. 
This value is in closed agreement with that extracted from the DLCP depth profile displayed in Fig. 5 and the difference between the defect densities at $100 \mathrm{~Hz}$ and $100 \mathrm{kHz}$ can be attributed to the deep level defect density of $1.27 \times 10^{16} \mathrm{~cm}^{-3}$ (Fig. 7).



Fig. 7. Defect density from DLCP measurements. The lower dashed line indicates the defect density interpreted as the carrier concentration and the difference between the dashed lines represent the deep level defect density.

\section{C. $J-V \& E Q E$ Analysis}

Table I summarises the PV parameters of the best cell from the device at room temperature (under $1000 \mathrm{~W} / \mathrm{m}^{2}$ ). The device consists of 16 cells with each a cell area of $0.25 \mathrm{~cm}^{2}$.

TABLE I

PV PARAMETERS OF THE BEST CELL FROM SB DOPED DEVICE

\begin{tabular}{|c|c|c|c|c|c|}
\hline & $\begin{array}{c}V_{o c} \\
{[\mathrm{mV}]}\end{array}$ & $\begin{array}{c}\boldsymbol{J}_{s c} \\
{\left[\mathrm{~mA} / \mathrm{cm}^{2}\right]}\end{array}$ & $\begin{array}{c}\mathbf{F F} \\
{[\%]}\end{array}$ & $\begin{array}{c}\boldsymbol{R}_{\boldsymbol{s}} \\
{\left[\Omega \mathrm{cm}^{2}\right]}\end{array}$ & $\begin{array}{c}\boldsymbol{R}_{\mathbf{s h}} \\
{\left[\Omega \mathbf{c m}^{2}\right]}\end{array}$ \\
\hline $\begin{array}{c}\text { CIGS_Sb } \\
\text { A_0.2\% }\end{array}$ & 556 & 29.7 & 62.6 & 0.539 & 327.4 \\
\hline
\end{tabular}

The JVT technique is a valuable tool for characterization of the recombination mechanisms which limit the performance of PV devices. Fig. 8 shows the JVT measurements for the best cell. The strong temperature dependence of short circuit current density, $\left(J_{s c}\right)$ may be attributed to the interface between the larger and smaller grains of CIGS absorber layer shown in the SEM image (Fig. 11), since only this region is close enough to the junction to cause this effect [12]. There is a roll-over effect appearing at low temperatures in this cell.
The linear extrapolation to $\mathrm{T}=0 \mathrm{~K}$ of the open circuit voltage $\left(V_{o c}\right)$ versus temperature curve gives the activation energy $E_{a}$ for recombination mechanisms in the device. We observe that our $V_{o c}(T)$ data for the best cell yields an activation energy $E_{a}=1.15 \mathrm{eV}$ (Fig. 9), which is consistent with the bandgap $\left(E_{g}=1.15 \mathrm{eV}\right)$ value determined from EQE data (Fig. 10). This indicates that the main recombination mechanism in the cell is the Schottky-Read-Hall recombination in the bulk, which is common for CIGS solar cells [13].

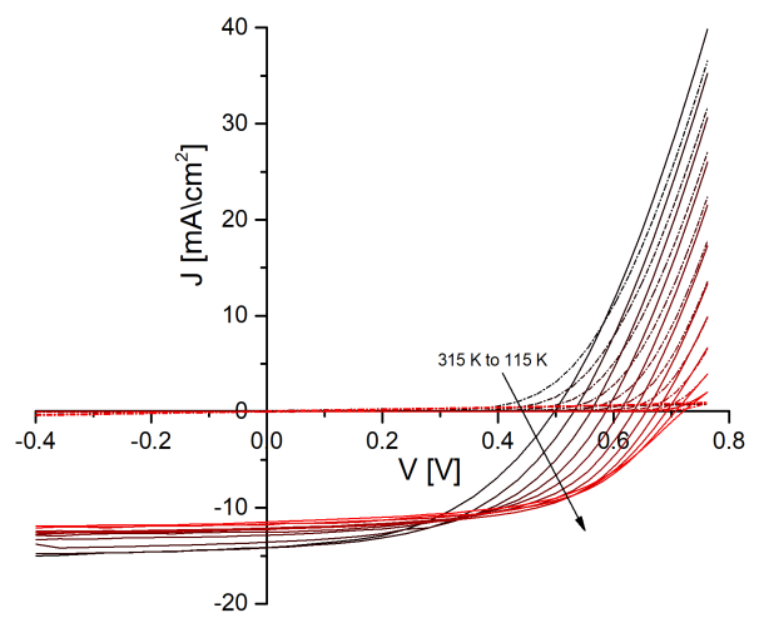

Fig. 8. The dark and illuminated $\left(500 \mathrm{~W} / \mathrm{m}^{2}\right) \mathrm{J}-\mathrm{V}$ curves are displayed for temperatures between 105 and $315 \mathrm{~K}$ (in $10 \mathrm{~K}$ steps). The crossover occurs in the whole temperature range and increases for decreasing temperatures.

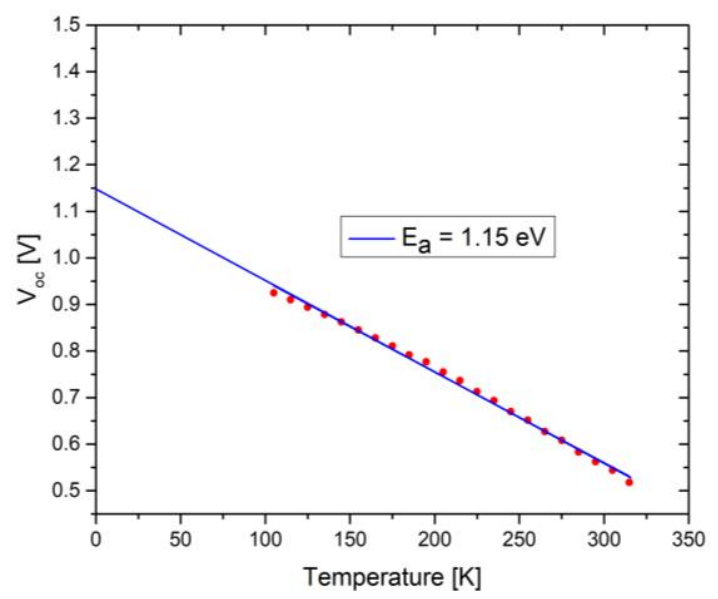

Fig. 9. Temperature dependence of $V_{o c}$ data, determined by the illuminated $\mathrm{J}-\mathrm{V}$ curves from Fig. 8, yielding an activation energy for recombination, $E_{a}=1.15 \mathrm{eV}$. 
The EQE spectra for the best cell is shown in Fig. 10. It has a high collection just above $80 \%$ in the range of 500 to 700 $\mathrm{nm}$ and a gradual decay of the EQE at longer wavelengths. This may be attributed to recombination losses as a result of incomplete generation or collection in the fine-grain absorber layer. The small decay below $480 \mathrm{~nm}$ is due to the absorption in the CdS layer. The EQE yields $J_{s c}$ of $30.5 \mathrm{~mA} / \mathrm{cm}^{2}$, which is in closed agreement with $J_{s c}$ from $\mathrm{J}-\mathrm{V}$ measurements shown in Table I.

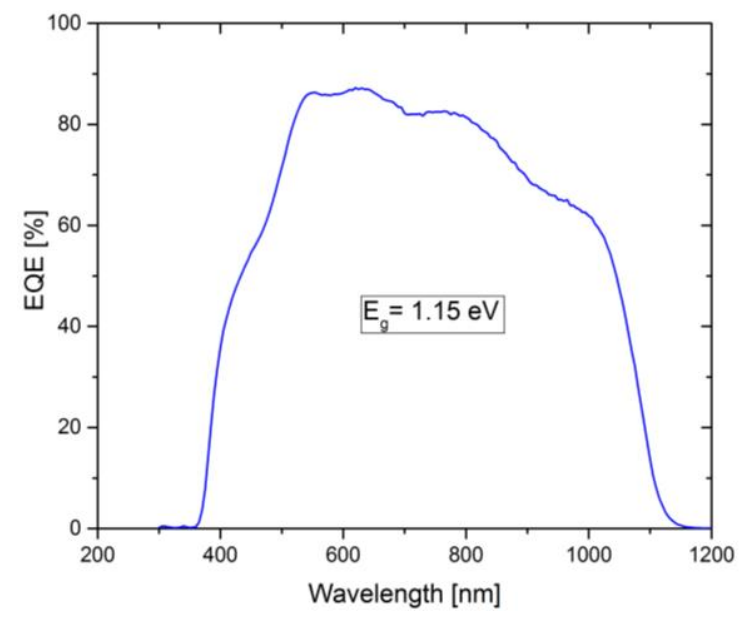

Fig. 10. The EQE spectra of the best cell. The absorber band gap is extracted from the peak of the derivative of the long wavelength slope in the EQE data.

\section{SEM Images}

The microstructure of the best cell is shown in the SEM image in Fig. 11. A bilayer structure of large-grain top layer and a fine-grain bottom layer is observed. It agrees with the trend observed from the EQE spectra, where large grains follow the range of 500-700 $\mathrm{nm}$ with a high EQE signal and fine grains correspond to the absorption range of 700-1000 nm with a low EQE signal. The absorber layer morphology contains some voids which can act as recombination centers which limit the solar cell device performance.



Fig. 11. The SEM cross-section of the best cell with a large-grain top layer and a fine-grain bottom layer of the absorber layer.

\section{E. EL Images}

The EL image shown in Fig. 12 for the best cell was performed under a current load of $\sim J_{s c}$. It shows inhomogeneous patterns of dark and bright regions over the cell area. These might be due to random crystal CIGS grains, presence of local shunts or grain boundary recombination in the absorber layer [14]. Brighter regions around the front contact grid may be attributed to higher losses across the TCO when the collection occurs further from where the injection current was applied.



Fig. 12. EL image of the best cell. The image maps the electronic quality of the absorber with higher counts showing areas of higher radiative recombination and lower counts or dark regions corresponding to small cracks, scratches or low material quality.

\section{CONCLUSIONS}

Antimony was introduced in the absorber layer for hydrazine-free solution-processed CIGS solar cells. The effect of antimony on the device performance was investigated. DLCP technique was used for estimating the carrier concentration as it is more sensitive technique to bulk states. From $V_{o c}$ vs temperature analysis, activation energy of recombination mechanism agrees well with the band gap of the absorber layer which indicates that the main recombination mechanism in the device is in the bulk. Deep level defects have been studied by Admittance Spectroscopy. We interpret the N1 step as a result of shallow interface states with an activation energy estimated to be $42 \mathrm{meV}$.

\section{REFERENCES}

[1] K. Ramanathan, J. Keane, R. Noufi, and L. B. Vista, "Properties of High-Efficiency CIGS Thin-Film Solar Cells," no. February, 2005.

[2] T. G. and D. B. M. Teodor K. Todorov, Oki Gunawan, "Solution-processed $\mathrm{Cu}(\mathrm{In}, \mathrm{Ga})(\mathrm{S}, \mathrm{Se})_{2}$ absorber yielding a 15.2\% efficient solar cell," Prog. Photovolt Res. Appl., 2012.

[3] P. Arnou, M. F. A. M. Van Hest, C. S. Cooper, A. V. Malkov, J. M. Walls, and J. W. Bowers, "Hydrazine-Free SolutionDeposited CuIn(S,Se) 2 Solar Cells by Spray Deposition of Metal Chalcogenides," ACS Appl. Mater. Interfaces, vol. 8, no. 19, pp. 11893-11897, 2016. 
[4] R. Herberholz, M. Igalson, and H. W. Schock, "Distinction between bulk and interface states in $\mathrm{CuInSe}_{2} / \mathrm{CdS} / \mathrm{ZnO}$ by space charge spectroscopy," J. Appl. Phys., vol. 83, no. 1, pp. 318325,1998

[5] D. L. Losee, "Admittance spectroscopy of impurity levels in Schottky barriers," J. Appl. Phys., vol. 46, no. 5, pp. 2204-2214, 1975.

[6] L. M. Mansfield, D. Kuciauskas, P. Dippo, J. V Li, K. Bowers, and B. To, "Optoelectronic Investigation of Sb-doped $\mathrm{Cu}(\mathrm{In}, \mathrm{Ga}) \mathrm{Se}_{2}$," vol. 2, pp. 2-5, 2015.

[7] P. Arnou et al., "Solution processing of $\mathrm{CuIn}(\mathrm{S}, \mathrm{Se})_{2}$ and $\mathrm{Cu}(\mathrm{In}, \mathrm{Ga})(\mathrm{S}, \mathrm{Se})_{2}$ thin film solar cells using metal chalcogenide precursors," Thin Solid Films, vol. 633, pp. 76-80, 2016.

[8] T. Eisenbarth, T. Unold, R. Caballero, C. A. Kaufmann, and H. W. Schock, "Interpretation of admittance, capacitance-voltage, and current-voltage signatures in $\mathrm{Cu}(\mathrm{In}, \mathrm{Ga}) \mathrm{Se}_{2}$ thin film solar cells," J. Appl. Phys., vol. 107, no. 3, 2010.

[9] J. T. Heath, J. D. Cohen, and W. N. Shafarman, "Bulk and metastable defects in $\mathrm{CuIn}_{1-\mathrm{x}} \mathrm{Ga}_{\mathrm{x}} \mathrm{Se}_{2}$ thin films using drive-level capacitance profiling," J. Appl. Phys., vol. 95, no. 3, pp. 10001010, 2004.
[10] G. Zapalac, K. Demirkan, and N. Mackie, "Drive-level capacitance profiling of $\mathrm{Cu}(\mathrm{In}, \mathrm{Ga}) \mathrm{Se}_{2}$ solar cells for different Cu/III ratios," 2014 IEEE 40th Photovolt. Spec. Conf. PVSC 2014, no. 2, pp. 452-455, 2014.

[11] A. S. Gilmore, V. Kaydanov, T. R. Ohno, D. H. Rose, S. D. Feldman, and P. Erslev, "Treatment effects on deep levels in CdTe based solar cells," 29th IEEE Photovolt. Spec. Conf., pp. 604-607, 2002.

[12] A. Duchatelet, K. Nguyen, P. Grand, D. Lincot, and M. Paire, "Self-aligned growth of thin film $\mathrm{Cu}(\mathrm{In}, \mathrm{Ga}) \mathrm{Se}_{2}$ solar cells on various micropatterns," vol. 253901, 2016

[13] S. S. Hegedus and W. N. Shafarman, "Thin-film solar cells: device measurements and analysis," Prog. Photovoltaics Res. Appl., vol. 12, no. 23, pp. 155-176, 2004.

[14] Y. M. Shin, C. S. Lee, D. H. Shin, H. S. Kwon, B. G. Park, and B. T. Ahn, "Surface modification of CIGS film by annealing and its effect on the band structure and photovoltaic properties of CIGS solar cells," Curr. Appl. Phys., vol. 15, no. 1, pp. 18$24,2015$. 